\title{
A study of hepatitis C prevalence in healthcare workers in the West of Scotland
}

D Thorburn, D Dundas, E A B McCruden, S O Cameron, D J Goldberg, I S Symington, A Kirk, P R Mills

\begin{abstract}
Background and aims-Whether healthcare workers have an increased prevalence of hepatitis $C$ virus infection as a result of exposure to patient's blood and body fluids is controversial. This study assesses the prevalence of hepatitis $C$ virus infection in healthcare workers, and its relation to the performance of exposure prone procedures and duration of occupational exposure, allowing an estimate to be made of the incidence of occupationally acquired hepatitis $\mathrm{C}$ infection among medical staff.
\end{abstract}

Methods-In this anonymous retrospective cohort study, we estimated the prevalence of hepatitis C infection in 10654 healthcare workers. ELISA-3 testing was performed on pools of five sera collected during immunisation against hepatitis $B$. Healthcare workers were arranged into five occupational groups, according to the degree of patient exposure, and three age bands ( $<30$ years, $30-39$ years, $>40$ years). Results-Prevalence of antibodies to hepatitis C was $0.28 \%$ (30/10 654), comparable in all occupational groups $(p=0.34)$ and unrelated to duration of potential exposure. Assuming that all detected infections had been occupationally acquired, the maximum estimated risk of hepatitis $C$ infection in exposure prone medical staff was low: $1.4 \%$ for surgeons and $1.0 \%$ for physicians over a 35 year professional career.

Conclusions-Hepatitis C infection is infrequent in healthcare workers in Glasgow. Those conducting exposure prone procedures do not seem to be at higher risk than other healthcare staff.

(Gut 2001;48:116-120)

Keywords: hepatitis C virus; epidemiology; exposure prone procedures; healthcare worker

Health, North Glasgow Hospitals University NHS Trust, Glasgow

G1 1JA, UK

I S Symington

Cardiothoracic Unit, Western Infirmary, Glasgow G11 6NT, UK A Kirk

Correspondence to: Dr P R Mills, Level 8, Gartnavel General Hospital, 1053 Great Western Road, Glasgow G12 0YN, UK gqna14@udcf.gla.ac.uk

Accepted for publication 18 July 2000 morbidity and mortality. ${ }^{1}$ The incidence of HCV seroconversion after accidental needlestick exposure is uncertain, with reports ranging from 0 to $10 \% .^{2-5}$ Whether healthcare workers have a higher prevalence of hepatitis C virus infection than the general population through percutaneous occupational exposure is unclear. ${ }^{6-12}$ The aim of this study was to assess the prevalence of $\mathrm{HCV}$ antibodies in healthcare workers in Glasgow, a city where injecting drug use is common, and to analyse rates in relation to specific occupational groupings and duration of potential exposure to HCV. The study focused in particular on staff performing exposure prone procedures, where injury to the worker may result in the exposure of the patient's open tissues to the blood of the worker. These rates were then compared with existing prevalence data in other local populations to determine if certain health care workers may be at increased risk of occupationally acquired HCV.

\section{Methods}

SETTING

This study was performed in the Greater Glasgow Health Board area, which incorporates the largest city in Scotland with a population of 909000 in 1996. It is estimated that approximately $80 \%$ of Glasgow's large injecting drug user population have been infected with HCV. ${ }^{13}{ }^{14}$ Glasgow is served by eight NHS hospital trusts providing a full range of clinical services, a single diagnostic virology laboratory service (Regional Virus Laboratory), and a coordinated occupational health service integrated into each NHS trust.

STUDY POPULATION

All healthcare workers in Glasgow who presented for hepatitis B virus (HBV) immunisation between October 1994 and October 1997 and had serum samples stored for anti-HBs assay were identified. Employees from one NHS trust, which denied ethics approval, were excluded.

Of the 24077 serum samples received by the Regional Virus Laboratory from healthcare staff, there were 11577 individuals that had occupational health case notes available after duplicate samples had been removed. Samples from 10654 (92\%) of these healthcare workers were located in the virology serum archive. According to 1997 Scottish Health Statistics payroll data, this sample represents $44 \%$ of the 24150 healthcare workers employed in the seven Glasgow NHS hospital trusts studied (personal communication). Included are: 1430 of $1972(73 \%)$ hospital medical staff, 203 of $547(37 \%)$ dentists, 5913 of $11803(50 \%)$
Abbreviations used in this paper: $\mathrm{HCV}$, hepatitis $\mathrm{C}$ virus; HBV, hepatitis B virus; RT-PCR, reverse transcriptase-polymerase chain reaction. 
Table 1 Occupational categories and age bands of healthcare workers tested for antibodies to hepatitis $C$

\begin{tabular}{|c|c|c|c|c|}
\hline \multirow[b]{2}{*}{ Occupational category } & \multicolumn{4}{|c|}{ No confirmed positive /No tested (prevalence, \%) } \\
\hline & $<30$ years & 30-39 years & 39 years & Total \\
\hline \multicolumn{5}{|l|}{ Staff conducting exposure prone procedures } \\
\hline Surgeons & $0 / 196$ & $0 / 154$ & $1 / 88$ & $1 / 438(0.23 \%)$ \\
\hline Physicians & $0 / 84$ & $0 / 156$ & $1 / 69$ & $1 / 309(0.32 \%)$ \\
\hline Dental staff & $0 / 296$ & $0 / 160$ & $1 / 120$ & $1 / 576(0.17 \%)$ \\
\hline Nurses ${ }^{\star}$ & $0 / 262$ & $2 / 366$ & $0 / 254$ & $2 / 882(0.23 \%)$ \\
\hline Subtotal & $0 / 838$ & $2 / 836(0.24 \%)$ & $3 / 531(0.56 \%)$ & $5 / 2205(0.23 \%)$ \\
\hline \multicolumn{5}{|l|}{ Staff in contact with patients and body fluids } \\
\hline Medical staff & $0 / 323$ & $0 / 232$ & $0 / 129$ & $0 / 684$ \\
\hline Nurses & $3 / 1072$ & $3 / 1086$ & $0 / 1176$ & $6 / 3334(0.18 \%)$ \\
\hline Psychiatric nurses & $2 / 184$ & $1 / 279$ & $1 / 217$ & $4 / 680(0.59 \%)$ \\
\hline Student nurses & $1 / 530$ & $1 / 78$ & $0 / 35$ & $2 / 643(0.31 \%)$ \\
\hline Paramedical staff $\dagger$ & $0 / 273$ & $2 / 139$ & $2 / 171$ & $4 / 583(0.69 \%)$ \\
\hline Portering staff & $0 / 78$ & $1 / 78$ & $0 / 127$ & $1 / 283(0.35 \%)$ \\
\hline Subtotal & $6 / 2460(0.24 \%)$ & $8 / 1892(0.42 \%)$ & $3 / 1855(0.16 \%)$ & $17 / 6207(0.27 \%)$ \\
\hline Laboratory medical and technical staff & $0 / 156$ & $3 / 139$ & $0 / 238$ & $3 / 533(0.56 \%)$ \\
\hline Staff with patient contact onlył & $1 / 299$ & $1 / 347$ & $0 / 592$ & $2 / 1238(0.16 \%)$ \\
\hline Staff with no patient contact $\$$ & $0 / 116$ & $3 / 136$ & $0 / 219$ & $3 / 471(0.64 \%)$ \\
\hline Total all categories & $7 / 3869(0.18 \%)$ & $17 / 3350(0.51 \%)$ & $6 / 3435(0.17 \%)$ & $30 / 10654(0.28 \%)$ \\
\hline
\end{tabular}

†Includes physiotherapists, chiropodists, radiographers, cardiology staff, medical illustration, and speech and occupational therapists.

*Includes midwifery staff, theatre, intensive care unit, accident and emergency, and renal unit nursing staff.

¥Includes staff in audiology, dietetics, optics, pharmacy, physics, psychology, social work, and ward clerical staff.

IIncludes administrative, catering, clerical, security, and catering staff.

nursing and midwifery staff, and 3108 of 9828 $(32 \%)$ others.

STUDY PROCEDURE

This study was necessarily performed in an anonymous manner. Serum samples were initially linked to the corresponding employee's immunisation records at the occupational health clinics using a database consisting of employee's name, sex, date of birth, location of employment, and occupational group. When data collection was complete, the age of each employee at the time of sample collection was derived. Individuals were then grouped into one of five occupational categories by their degree of patient exposure and into three age bands (table 1) to ensure that any combination of the two contained more than 50 individuals, thus protecting any infected individual against identification. All employee identifiers were then deleted from the database leaving only non-identifying details of occupational category and age band, linked to the stored serum laboratory number.

A unique non-identifying code was generated for each database entry and printed on labels adjacent to the corresponding laboratory serum number. The appropriate sera were then labelled with their unique code and transferred to a separate laboratory for testing. By then deleting the laboratory serum numbers from the database, the HCV antibody results could only be linked with the anonymous data (occupational category and age band) via the unique non-identifying code.

SAMPLES FOR TESTING

Sera were initially stored by sequential laboratory number at either $4^{\circ} \mathrm{C}$ or $-20^{\circ} \mathrm{C}$ on the day of collection in the virology department. The study sera were then identified, aliquoted into $2.5 \mathrm{ml}$ Sarstedt vials, labelled with the unique non-identifying code, and stored at $-20^{\circ} \mathrm{C}$ for testing.

\section{HEPATITIS C TESTS}

Sera were screened for antibodies to HCV by ELISA-3 (Ortho Diagnostics, Raritan, New Jersey, USA). Reactive samples were only considered positive if they were confirmed by RIBA-3 testing (Ortho Diagnostics). All samples confirmed positive were further tested for the presence of HCV RNA by reverse transcriptase-polymerase chain reaction (RTPCR) using an inhouse method. ${ }^{15}$ RT-PCR positive samples were genotyped by restriction fragment length polymorphism. ${ }^{16}$

In view of the large number of sera to be tested, a pooling protocol was developed. Pools of five sera were tested by third generation ELISA. Twenty microlitres of each of the five sera to be tested were pooled and mixed thoroughly. A sample of this pool $(50 \mu \mathrm{l})$ was transferred into the test plate (the equivalent of $10 \mu \mathrm{l}$ of each serum), diluent was added to a total volume of $200 \mu \mathrm{l}$, and thereafter testing followed the Ortho ELISA-3 protocol. The final dilution of each individual serum in the pool was 1 in 20 compared with individual testing with a 1 in 11 dilution. The five sera in any reactive pool were then tested individually by ELISA-3 to identify the reactive samples requiring confirmatory testing by RIBA-3.

\section{STATISTICS}

Data were analysed for the prevalence of antibodies to HCV in each age band and occupational group. The prevalence in each of these categories was compared using the $\chi^{2}$ test or Fisher's exact test.

By assuming that 24 years is the median age at which doctors qualify in the UK, the probability of acquiring HCV per 100 personyears of occupational exposure for the medical staff was estimated to be:

Probability of HCV infection /100 personyears exposure $=($ Number positive for $\mathrm{HCV}$ antibodies $\times 100 /$ Number tested $\times$ (median age in occupational group-24)) 
Table 2 Comparison of ELISA-3 hepatitis $C$ virus (HCV) antibody test on individual and pooled sera from 2190 healthcare workers who conduct exposure prone procedures

\begin{tabular}{llrr}
\hline & \multicolumn{2}{l}{ Pooled sera } & \\
\cline { 2 - 4 } & ELISA positive & ELISA negative & Total \\
\hline ELISA positive/RIBA positive & 5 & 0 & 5 \\
ELISA positive/RIBA indeterminate & 1 & 1 & 2 \\
ELISA positive/RIBA negative & 0 & 2 & 2 \\
ELISA negative & $2^{\star \star}$ & 427 & 429 \\
Total & 8 & 430 & 438 \\
\hline
\end{tabular}

$\star 438$ pools containing five sera each

${ }^{\star \star}$ That is, 10 sera tested in which no individual serum was ELISA or RIBA positive.

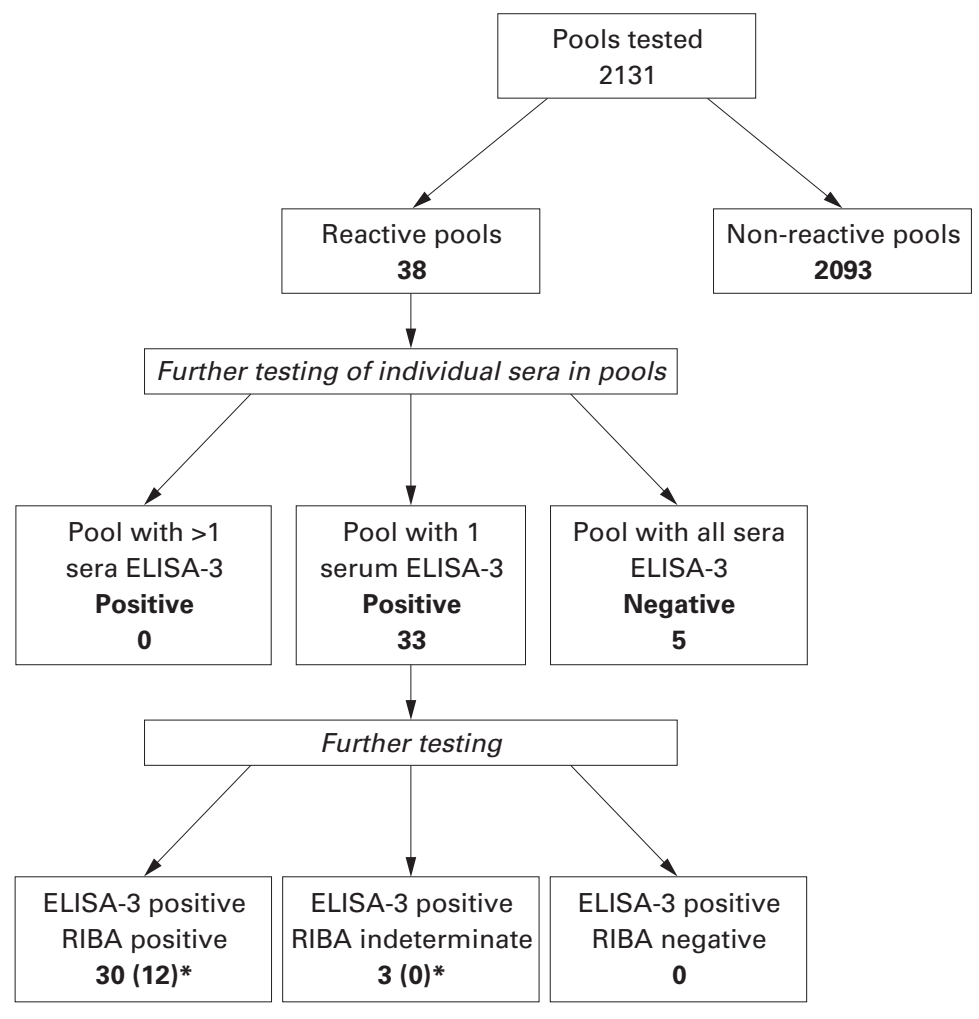

* Indicates numbers of sera positive by RT-PCR for HCV RNA

Figure 1 Results of testing sera from 10654 healthcare workers for antibodies to hepatitis $C$ virus (HCV) by ELISA-3 in pools of five.

This estimate is a maximum because it is possible that infections among $\mathrm{HCV}$ antibody positive individuals were acquired before healthcare work was commenced or through a non-occupational route. The median age for each occupational group was available from the dates of birth on the original database.

ETHICS

Ethics approval for this study was obtained from seven of the eight NHS trust research ethics committees in Glasgow. Employees of Yorkhill NHS University Trust, which did not grant approval, were excluded.

\section{Results}

EVALUATION OF POOLING

The pooling method was evaluated on the first 2190 serum samples from employees in exposure prone occupations. They were initially tested individually and then arranged into 438 pools and tested by a single operator blinded to the location of the known positive samples (table 2). Nine of these pools contained a single serum sample known to be reactive when tested individually by ELISA-3. On pooled testing, all five sera confirmed positive by RIBA-3 individual testing and one serum considered indeterminate by RIBA-3 testing (C33 2+ band only) were detected. Two pools were reactive when individual ELISA-3 and RIBA-3 testing confirmed all 10 sera to be unreactive (false positive pools). Three pools containing sera known to be reactive by individual ELISA-3 testing were unreactive. Two of these pools contained single samples which were RIBA-3 negative and considered false positives for antibodies to $\mathrm{HCV}$ and one was of indeterminate RIBA-3 reactivity (C33 $2+$ band only) and hence of doubtful significance. With confirmatory testing by RIBA-3, our method of pooling had a sensitivity of $100 \%(5 / 5)$ and specificity of $100 \%(433 / 433)$ for samples that were confirmed positive for antibodies to $\mathrm{HCV}$.

\section{HCV PREVALENCE}

Thirty eight $(1.8 \%)$ of the 2131 pools tested were reactive by ELISA-3 and individual sera were analysed further (fig 1). The overall prevalence of $\mathrm{HCV}$ antibodies was $0.28 \%$ (30/ $10654,95 \%$ confidence interval $0.19-0.41 \%)$. Occupational category and age band of employees tested are summarised in table 1 . There was no statistically significant difference in the prevalence of HCV antibodies between the five occupational categories $(p=0.34)$ or between exposure prone staff and all non-exposure prone staff $(0.23 \%$ v $0.30 \%$; $\mathrm{p}=0.59$ ). The prevalence of antibodies to $\mathrm{HCV}$ was significantly higher in the 30-39 year age band $(\mathrm{p}=0.012)$.

Twelve $(40 \%)$ of the 30 sera confirmed to contain antibodies to $\mathrm{HCV}$ had viral RNA detectable in serum by RT-PCR. These were typed as follows: six type 1 , four type 3 , one type 5, and one could not be typed.

PROBABILITY OF HCV INFECTION

Within the exposure prone category, median age and age ranges for each occupational group were: surgeons 30 years (22-62 years); physicians 34 years (22-63 years); dental staff 29 years (16-72 years); and nurses 34 years (17-64 years).

The maximum estimated probability of occupationally acquired $\mathrm{HCV}$ infection per 100 person-years in the exposure prone group was 0.04 for surgeons and 0.03 for physicians, which would equate to a $1.4 \%$ and $1 \%$ risk, respectively, over a professional career of 35 years.

\section{Discussion}

Hepatitis C is a blood borne virus transmitted by the parenteral route. Infection frequently results in a chronic asymptomatic carrier state for many years before the development of symptomatic liver disease. $\mathrm{HCV}$ infected healthcare workers may therefore be unaware of their condition and their potential to infect patients. Healthcare workers, who perform exposure prone procedures, where injury to the 
worker may result in exposure of the patient's open tissues to the blood of the worker, are theoretically at increased risk of infection with blood borne viruses. According to UK health department guidelines, these occupations include surgeons, interventional physicians, and intensive care unit and accident and emergency staff. If occupational transmission of $\mathrm{HCV}$ was common, staff performing exposure prone procedures might be expected to have a higher prevalence of hepatitis $\mathrm{C}$ antibodies compared with staff in less exposed occupations. Our results revealed that the overall prevalence of hepatitis $\mathrm{C}$ antibodies in healthcare workers in Glasgow was low $(0.28 \%)$ and comparable with those reported in two smaller studies from England. ${ }^{56}$ The data indicate that the performance of exposure prone procedures does not frequently result in the acquisition of $\mathrm{HCV}$ by healthcare workers (exposure prone $0.23 \%$ v non-exposure prone $0.30 \% ; p=0.59$ ). The prevalence of $\mathrm{HCV}$ antibodies among surgeons (only one $(0.23 \%)$ of 438 tested), the group perceived to be at greatest risk of occupational exposure, was comparable with that observed among healthcare workers who have had little or no patient contact, including student nurses. However, the similar prevalence may not reflect similar routes of infection and we were unable to explore the presence of other risk factors for HCV transmission with this study design. Needlestick injuries to surgeons in operating theatres are common (15.5 per operator per 1000 operations).$^{17}$ Even if we assume that all infections in exposure prone staff were occupationally acquired, the estimated maximum probability of occupationally acquired $\mathrm{HCV}$ infection in surgeons is $1.4 \%$ ( 1 in 70 ) over a surgical career of 35 years $(0.04$ per 100 person years). This value agrees with a model based estimate of professional lifetime risk of $\mathrm{HCV}$ infection for a French surgeon of $0.3-3.1 \%{ }^{18}$.

Studies have reported a higher prevalence of antibodies to HCV in healthcare workers compared with blood donors but they are nonrepresentative self selected group and persons with high risk behaviour are excluded. ${ }^{67}$ The prevalence of antibodies to $\mathrm{HCV}$ in the Glasgow population is unknown. From 1991 to 1997, 2161 individuals tested positive for HCV in the Greater Glasgow Health Board catchment area (prevalence $0.24 \%$ (2161/ $905100)) .{ }^{19}$ This is likely to be an underestimate of the true population prevalence but is comparable with the prevalence recorded in healthcare workers in this study $(0.28 \% v$ $0.24 \%$; $=0.42$ ). A mixed population of hospital attenders (male outpatients or inpatients, aged 16-49 years) at two of the general hospitals in our study were screened for $\mathrm{HCV}$ antibodies from July to December 1997 using the same pooling protocol (manuscript in preparation). The prevalence of antibodies to HCV in this population was $4.0 \%(107 / 2702$ individuals tested), significantly higher than the healthcare worker population prevalence $(0.28 \%$ v $4.0 \% ; \mathrm{p}<0.0001)$. Thus healthcare workers, including those performing exposure prone procedures, have an estimated prevalence of antibodies to $\mathrm{HCV}$ which does not exceed that already known in the local population and is less than that in a cohort of their male hospital patients.

Pooling of sera allowed us to increase the number of third generation ELISA tests performed without loosing sensitivity or generating an unacceptable number of false positives requiring further testing. This is in keeping with earlier reports using similar pooling methods with second generation ELISA kits for epidemiological studies in low prevalence populations. ${ }^{20}{ }^{21}$ Of the 30 healthcare workers with antibodies to HCV, only 12 were found to be viraemic. This may reflect the suboptimal storage conditions of sera for RNA analysis. Alternatively, it may reflect the high rate of clearance of HCV RNA from serum of healthy individuals exposed to HCV many years previously. ${ }^{22}$ Most viraemic patients were infected with genotype 1 (six, 50\%) or genotype 3 (four, $33 \%$ ), similar to our local clinic population where genotypes 1 and 3 occur with equal frequency. One individual was infected with genotype 5, suggesting acquisition of infection abroad.

The risk posed to patients by a HCV infected healthcare worker is not known and there are no guidelines to assist in their management. There have been reports of $\mathrm{HCV}$ transmission to patients as a consequence of inadequate infection control procedures and by negligent medical practices. ${ }^{23}{ }^{24}$ There has been only a single published report of HCV transmission from an infected cardiac surgeon to five patients despite universal precautions having been observed. ${ }^{25}$ Provided that appropriate infection control policies are followed, patients and healthcare managers should be reassured by the low reported prevalence of $\mathrm{HCV}$ infected healthcare workers in the health service.

Healthcare personnel and patients can both be reassured that the reservoir of healthcare personnel in the West of Scotland who are infected with HCV is extremely small (2.8 per 1000). It appears that working in the healthcare environment and performing exposure prone procedures, in an area with a large $\mathrm{HCV}$ infected injecting drug using population, only rarely leads to acquisition of HCV by healthcare workers. The risk that a patient may become infected by contact with the health service is probably low. However, these findings should not lead to any complacency in the implementation of universal precautions and the reporting and follow up of needlestick injuries.

The authors would like to thank Dr A Speekenbrink and $\mathrm{Mr}$ Graeme Gillespie for assistance in managing the Regional Virus Laboratory database and the support of Mr William Smyth and Laboratory database and the support of $\mathrm{Mr}$ William Smyth and $\mathrm{Mr}$ Glenn Codere in programming and managing the study database. We would also like to acknowledge the help of Mrs Linda McDonald and Mrs Elaine Murray for pooling and ELISA testing the sera and Ms Parvez Murad for PCR testing and genotyping the ELISA reactive samples. Finally, we thank all of the staff of the occupational health departments in Glasgow for their assistance and cooperation over the duration of this study. The study was funded by the Department of Health at the Scottish Office (project number K/OPR/2/2/ D321).

1 Niederau C, Lange S, Heintges T, et al. Prognosis of chronic hepatitis C: Results of a large, prospective cohort study. Hepatology 1998;28:1687-95. 
2 Kiyosawa $\mathrm{K}$, Sodeyama T, Tanaka E, et al. Hepatitis C in hospital employees with needlestick injuries. Ann Intern hospital employees with

3 Mitsui T, Iwano K, Masuko K, et al. Hepatitis C virus infection in medical personnel after needlestick accident. Hepatology 1992;16:1109-14.

4 Lanphear BP, Linnemann CC Jr, Cannon CG, et al. Hepatitis $\mathrm{C}$ virus infection in healthcare workers: risk of exposure and infection. Infect Control Hosp Epidemiol 1994; 15:745-50.

5 Puro V, Petrosillo N, Ippolito G. Italian Study Group on Occupational Risk of HIV and Other Bloodborne Infections. Risk of hepatitis C seroconversion after occupational exposures in health care workers. Am f Infect Control 1995; 23:273-7.

6 Zuckerman J, Clewley G, Griffiths P, et al. Prevalence of hepatitis $\mathrm{C}$ antibodies in clinical health-care setting. Lancet 1994;343:1618-20

7 Neal KR, Dornan J, Irving WL. Prevalence of hepatitis C antibodies among healthcare workers of two teaching hosantibodies among healthcare workers of two tea
pitals. Who is at risk? $B M \mathcal{F} 1997 ; 314: 179-80$.

8 Thomas DL, Factor SH, Kelen GD, et al. Viral hepatitis in health care personnel at the Johns Hopkins Hospital. Arch

9 Cooper BW, Krusell A, Tilton RC, et al. Seroprevalence of antibodies to hepatitis $\mathrm{C}$ virus in high-risk hospital personnel. Infect Control Hosp Epidemiol 1992;13:82-5.

10 Panlilio AL, Shapiro CN, Schable CA, et al. Serosurvey of human immunodeficiency virus, hepatitis B virus, and hepatitis $\mathrm{C}$ virus infection among hospital-based surgeons. f Am Coll Surg 1995;180:16-24.

11 Shapiro CN, Tokars JI, Chamberland ME, and the American Academy of Orthopedic Surgeons Serosurvey Study Committee. Use of hepatitis B vaccine and infection with hepatitis B and C among orthopaedic surgeons. F Bone foint Surg 1996;78-A:1791-800.

12 Thomas DL, Gruninger SE, Siew C, et al. Occupational risk of hepatitis $\mathrm{C}$ infections among general dentists and oral of hepatitis C infections among general dentists and oral

13 Frischer M, Leyland A, Cormack R, et al. Estimating population prevalence of injected drug use and HIV infection lation prevalence of injected drug use and HIV infection
among injecting drug users in Glasgow. Am $\mathcal{f}$ Epidemiol among injecting
14 Goldberg D, Cameron S, McMenamin J. Hepatitis C virus antibody prevalence among injecting drug users in Glasgow has fallen but remains high. Commun Dis Public Health 1998;1:95-7.

15 Dow BC, Coote I, Munro H, et al. Confirmation of hepatitis C virus antibody in blood donors. F Med Virol 1993;41: 215-20.

16 McOmish F, Chan S-W, Dow BC, et al. Detection of three types of hepatitis $\mathrm{C}$ virus in blood donors: investigation of type specific differences in serological activity and rate of type specific differences in serological activity and rate of 33:7-13.

17 Camilleri AE, Murray S, Imrie CW. Needlestick injury in surgeons: what is the incidence? f R Coll Surg Edinb 1991; 36:317-18.

18 Yazdanpanah Y, Boelle P-Y, Carrat F, et al. Risk of hepatitis $\mathrm{C}$ virus transmission to surgeons and nurses from infected patients: model-based estimates in France. F Hepatol 1999; 30:765-9.

19 Surveillance of known hepatitis $\mathrm{C}$ antibody positive cases in Scotland: results to December 31, 1997. SCIEH Weekly Report 1999;33:190-6.

20 Garcia Z, Taylor L, Ruano A, et al. Evaluation of a pooling method for routine anti-HCV screening of blood donors to lower the burden on blood banks in countries under development. F Med Virol 1996;49:218-22.

21 Liu P, Shi ZX, Zhang YC, et al. A prospective study of a serum-pooling strategy in screening blood donors for antibodies to hepatitis C virus. Transfusion 1997;37:732-6.

22 Grellier L, Brown D, Power J, et al. Absence of anti-envelope antibodies and clearance of hepatitis $\mathrm{C}$ virus in a cohort of rish women infected in 1977. F Viral Hepat 1997;4:37981

23 Hayashi J, Kishihara Y, Yamaji K, et al. Transmission of hepatitis $\mathrm{C}$ virus by healthcare workers in a rural area of Japan. Am f Gastroenterol 1995;90:794-9.

24 Bosch X. Hepatitis C outbreak astounds Spain. Lancet 1998;351:1415.

25 Esteban JI, Gomez J, Martell M, et al. Transmission of hepatitis C by a cardiac surgeon. N Engl f Med 1996;334:555-9. 